\title{
COMPARISON BETWEEN PHYSICO-MECHANICAL PROPERTIES OF THREE TYPES OF COMPOSITE RESINS
}

\author{
Mahmoud A Abdella*, Khaled M Noaman**, Alla N Syam*** and Saad S Elghazawy****
}

\begin{abstract}
The aim of this research was to evaluate the shear punch strength and creep for nano-composite, nanohybrid and low shrinkage composite. A total number of 126 resin composite specimens were used. They were divided into three groups $(\mathrm{n}=42)$ according to the type of resin composites (silorane $\{$ Filtek P90\}), (nanohybrid\{Filtek Z250XT\}),\& (nanofilled\{Filtek Z350 XT\}, each group was subdivided into two subgroups $(\mathrm{n}=21)$ for each laboratory test (shear strength $\&$ creep). The two main subgroups were further subdivided into three equal categories(n=7)according to immersion time in distilled water(24 hours, one week\& one month). The aesthetic light-cured resin composite specimens were cured by using LED light-curing unit. Shear strength\& creep tests were done by using universal testing machine. The data were subjected to statistical analysis using two-way ANOVA\& one- way ANOVA followed by pair- wise Duncn post- hoc tests were performed to detect level of significance of 5\% between subgroups. Comparison was made using the Tukey test with level of significance of 5\%. Statistical analysis was performed using Aasistat 7.6 statistics software for Windows (Campina Grande, Paraiba state, Brazil). P values $\leq 0.05$ are considered to be statistically significant in all tests. Statistical no difference was observed in shear strength between all groups for different periods (24-hour, one week \&one month). Statistical no difference in polymerization shrinkage between silorane \& nanofilled composites. Statistical no difference in creep between nano-hybrid \& nanofilled composites, while siloran composite recorded statistically significant lowest creep. In conclusion, the nanofilled composite showed significantly higher shear strength than the other composites. The nano-hybrid composite showed significantly higher creep than the other composites.
\end{abstract}

\section{INTRODUCTION}

The increasing attractiveness of tooth-colored restoration has promoted research in this particular area of restorative dentistry in the last few years. Resin composites are used extensively in tooth restoration because they are popular with both dentists and patients. Amongst other benefits, their color is similar to that of a real tooth, they have good physical properties and can be used in conservative cavity preparation ${ }^{(1)}$.

In recent years, resin composite materials have been on the market with improved mechanical properties due to new filling concepts, changes in the matrix and improvement in curing conditions ${ }^{(2)}$. It is well-documented that energy density of the light cure influences the degree of cure, depth of cure, and mechanical properties of a resin composite ${ }^{(3)}$.

Together with the advance of light-cured composites, light sources and light-curing techniques have also improved remarkably. Recently, LED (light emitting diodes) and high intensity light-curing devices, such as xenon plasma arc (PAC) and lasers, have been introduced for curing of dental composites, as an alternative to conventional QTH (quartz-tungsten halogen) units ${ }^{(4)}$. Which would assure the physical properties of the resulting resin composite restorations ${ }^{(5)}$.

\footnotetext{
* Demonstrator of Dental Biomaterials Department, Faculty of Dental Medicine, Al-Azhar University, (Assuit branch) ** Professor of Operative Dentistry Department, Faculty of Dental Medicine, Al-Azhar University

*** Lecturer of Dental Biomaterials Department, Faculty of Dental Medicine, Al-Azhar University (Assuit branch). **** Lecturer of Dental Biomaterials Department, Faculty of Dental Medicine, Al-Azhar University
} 
Composite resin is composed of four major components: organic resin matrix, inorganic filler particles, coupling agent and activator initiator system. The most common monomers are Bisphenol Glycidyl methacrylate (Bis-GMA), urethane dimethacrylate (UDMA) and triethylene glycol dimethacrylate (TEGDMA). Diluents must be added to reduce the high viscosity of Bis-GMA. TEGDMA are usually added to reduce the viscosity ${ }^{(6)}$. Incorporation of filler particles into a resin matrix greatly improves the properties especially if the filler particles are well bonded to the matrix. The inorganic filler particles may consist of glass or quartz (fine particles), colloidal silica (microfine particles), or zirconia-silica nanoclusters and silica nanoparticles. The primary purposes of filler particles are to strengthen the composite and to reduce the amount of matrix material resulting in reduction in polymerization shrinkage, thermal expansion, water sorption and staining ${ }^{(7)}$.

According to filler size and amount of filler composite resins classified into: Traditional Composite Resin, Microfilled, Small Particle-Filled, Hybrid, Microhybrid, Nanocomposites (Nanofilled, Nanohybrid ${ }^{(8)}$. Nanofilled Composite Resin was developed to be used in all cavities with high initial polish and superior polish retention (typical as microfilled composite), as well as excellent mechanical properties suitable for high stress-bearing restorations (typical as hybrid composites). Nanotechnology is known as the production and manipulation of materials and structures in the range of about 1-100 nanometers by various physical or chemical methods ${ }^{(9)}$.

Nanofillers are extremely small size, these fillers allow the particles to fit into spaces between other particles in a composite and effectively increasing the overall filler level. The filler loading is about 59 vol \%. Nanocomposites are now recommended for use in both anterior and posterior restorations ${ }^{(10-12)}$.

Several approaches have been pursued to reduce polymerization shrinkage in dental resins.
Using monomers based on spiroorthocarbonates $(\mathrm{SOC})^{(13)}$; trimethacrylate monomers ${ }^{(14)}$; cyclopolymerizable di- and multi-functional acrylate resins and a methacrylated derivative of styrene-allyl alcohol (MSAA). All of these approaches produced composites with slightly reduced polymerization shrinkage but with lower properties than Bis- GMAbased composites. Cycloaliphatic epoxy resins (oxiranes) have been investigated and proposed as photocurable, cationic polymerized resins for dental composites with nearly one-half of the polymerization shrinkage of Bis-GMA-based resins. But these resins have a relatively high-water sorption ${ }^{(15)}$.

Silorane-based composite is a low shrinkage tooth colored restorative material which has been recently introduced in the dental market. Silorane was so named by the manufacturer to indicate a hybrid compound of siloxane and oxirane functional groups. While the siloxane determines the highly hydrophobic nature of the siloranes, the cycloaliphatic oxirane functional groups are responsible for lower shrinkage when compared to methacrylate-based composites. Oxiranes, which are cyclic ethers, polymerized by a cationic ring-opening mechanism, while methacrylates polymerized via a free-radical mechanism ${ }^{(16,17)}$.

Silorane-based composite have lower contraction stress than the other composites and having similar modulus of elasticity. They have been shown to have low polymerization shrinkage, good stability and insolubility in biological fluid simulants. This new monomer system may be a promising solution to overcoming the negative effect of oral fluids on

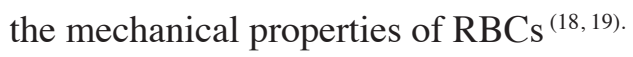

Resinous materials absorb water and it has been reported that this property has detrimental effects on the composite material ${ }^{(20)}$. The absorption of water molecules by hydrophilic moieties within resin based composite material on exposure to the oral environment may result in hydrolytic degradation and filler particle and resin matrix de-bonding, 
thereby decreasing the mechanical properties of the material ${ }^{(21)}$.

However, there is a few data are available regarding the properties of resin composites. So, this study will be done to evaluate the shear punch strength and creep for nano-filled, nano-hybrid and low shrinkage composites.

\section{MATERIALS AND METHODS}

\section{Materials:}

Three different resin composite materials of the same color shade (A2) were used in this study. The different resin composites are low shrinkage composite (Filtek P90)\}, \{the nano-hybrid composite (Filtek Z $250 \mathrm{XT}$ ) and the nano-filled composite (Filtek Z 350 XT).

\section{Methods:}

\section{Specimens Grouping:}

A total number of 126 resin composite specimens were used in this study. They were divided into three main groups $(\mathbf{n}=\mathbf{4 2})$; according to type of resin composite (A). ( $\left.\mathbf{A}_{1}\right)$ low shrinkage composite, (A) nano-hybrid composite and (A3) nano-filled composite. Each main group was subdivided into two subgroups $(\mathbf{n = 2 1})$ according to the used laboratory test $(\mathbf{B})$ : $\left(\mathbf{B}_{1}\right)$ shear strength and $\left(\mathbf{B}_{2}\right)$ creep.

The three-main subgroup were further subdivided into three subgroups $(\mathbf{n}=7)$ according to $(\mathbf{C})$ : $\left(\mathbf{C}_{\mathbf{1}}\right)$ 24 hours, $\left(\mathbf{C}_{2}\right)$ one week and $(\mathbf{C} 3)$ one month.

\section{Shear Strength:}

\subsection{Mold construction:}

Split Teflon mold was fabricated to made disc specimens with dimensions of ( $2 \mathrm{~mm}$ thickness, and $7 \mathrm{~mm}$ diameter). These dimensions were determined according to the recommendation of international standards organization ISO NO.4049 (2000)

\subsection{Specimens preparation:}

The mold was positioned over a glass slab then slightly overfilled with one of the composite. A Celluloid strip was placed and gently pressed on top of the surface of the mold to remove any excess material, to avoid the presence of air bubbles and to ensure smooth surface finish. The specimens were irradiated for 40s by LED light curing unit with a light output of $1000 \mathrm{~mW} / \mathrm{cm} 2$.The celluloid strip was removed and the mold was split to remove the specimen. The intensity of light was frequently tested with curing radiometer to be sure that it was always over $1000 \mathrm{mw} / \mathrm{cm}^{2}$. The specimens were stored in distilled water in an incubator at $\left(37 \pm 1^{\circ} \mathrm{C}\right)$ for periods of $24 \mathrm{~h}$, one week and one month

\subsection{Shear strength testing:}

The shear strength was tested by the shear punch test using Lloyd mechanical testing machine (Model LRX-plus; Lloyd Instruments Ltd., Fareham, UK). Each specimen was mounted on a universal testing machine in the lower attachment. In this test stainless steel punch with a flat end ( $2 \mathrm{~mm}$ diameter) was used to create the shear force by sliding through a punch hole having minimum clearance whilst at the same time creating minimal frictional force compared with the value of force required to fracture the test specimens. The speed of testing for these tests was $2.0 \mathrm{~mm} / \mathrm{min}$. The maximum load necessary to produce fracture of the specimens was recorded in Newton from the stress strain curve.

The calculation of shear strength is guided by the formulae:

Shear Strength $(\mathrm{MPa})=$ Force (Newton)

Section thickness $(\mathrm{mm}) \mathrm{x}$ Punch circumference $(\mathrm{mm})$

\section{Creep:}

\subsection{Mold construction:}

A specially designed split Teflon mold was fabricated to form cylindrical shape specimens with dimensions of $4 \mathrm{~mm}$ in diameter and $6 \mathrm{~mm}$ in height ${ }^{(22)}$. 


\subsection{Specimens preparation:}

Specimens' preparation as described before for shear strength.

\subsection{Creep testing:}

It is defined as the time-dependent plastic deformation, or strain, of a material under a static load will below its conventional elastic limit. It was performed on cylindrical-shaped specimen $(6 \mathrm{~mm}$ thickness and $4 \mathrm{~mm}$ diameter) at constant load 50 $\mathrm{MPa}$ on a uniaxial compression rig of a universal testing machine. The stresses were maintained for 2 hours and the resultant percentage compressive strains were recorded as a function of time.

\section{Statistical analysis}

Data analysis was performed in several steps. Initially, descriptive statistics for each group results. Two-way analysis of variance ANOVA test of significance comparing variables affecting mean values. One-way ANOVA followed by pairwise Duncn post-hoc tests were performed to detect significance between subgroups. Statistical analysis was performed using Aasistat 7.6 statistics software for Windows (Campina Grande, Paraiba state, Brazil). $\mathrm{P}$ values $\leq 0.05$ are considered to be statistically significant in all tests.

\section{RESULTS}

\section{Shear strength}

The interactions between variables (resin composite versus time) are shown in table (1). Silorane composite; it was found that month aging group recorded the highest shear strength mean value followed by $\mathbf{2 4 h r a g i n g ~ g r o u p ~ w h i l e ~ w e e k ~}$ aging group recorded the lowest mean value. The difference in shear strength mean values between composite groups was statistically significant $(\mathrm{P}<0.05)$.

Nano-hybrid resin composite; it was found that month aging group recorded the highest shear strength mean value followed by 24 hraging group while week aging group recorded the lowest mean value. The difference in shear strength mean values between composite groups was statistically significant $(\mathrm{P}<0.05)$.

Nano-filled resin composite; it was found that month aging group recorded the highest shear strength mean value followed by $24 \mathrm{hraging}$ group while week aging group recorded the lowest mean value. The difference in shear strength mean values between composite groups was statistically significant $(\mathrm{P}<0.05)$.

Table (1) Comparison of shear strength results (Mean values \pm SDs) as function of composite groups and artificial aging

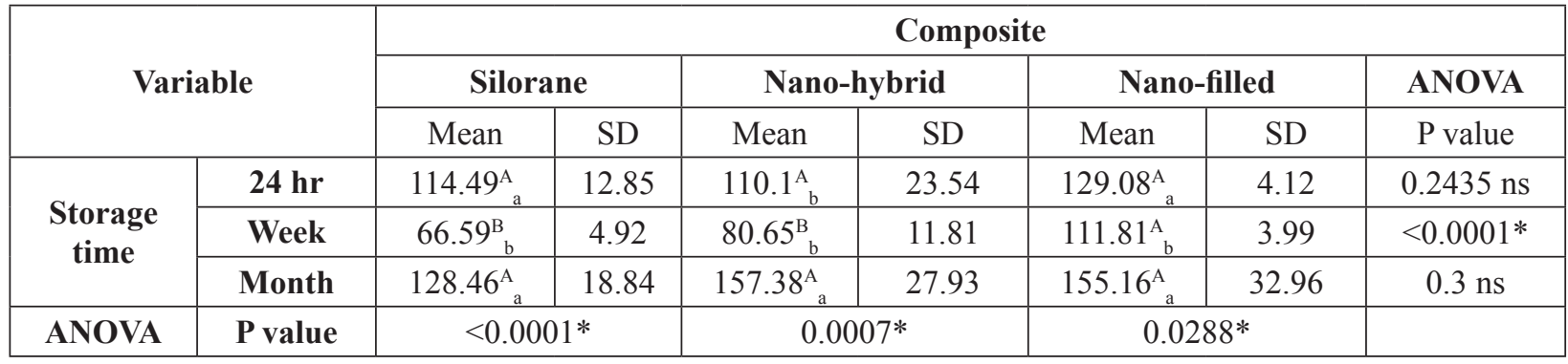

Different superscript letter in the same row indicating statistically significant between composite (Tukey's test; $p<0.05$ ).Different subscript letter in the same column indicating statistically significant between aging (Tukey's test; $p>0.05) * ;$ significant $(p<0.05) \quad$ ns; non-significant $(p>0.05)$ 


\section{Creep:}

The interactions between variables (resin composite versus time) are shown in table (2). Silorane composite; it was found that month aging group recorded the highest creep mean value followed by $\mathbf{2 4 h r}$ aging group while week aging group recorded the lowest mean value. The difference in creep mean values between composite groups was statistically significant $(\mathrm{P}<0.05)$.

Nano-hybrid resin composite; it was found that month aging group recorded the highest creep mean

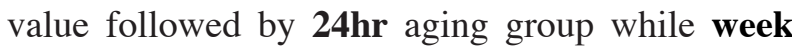
aging group recorded the lowest mean value. The difference in creep mean values between composite groups was statistically significant $(\mathrm{P}<0.05)$.

Nano-filled resin composite; it was found that month aging group recorded the highest creep mean

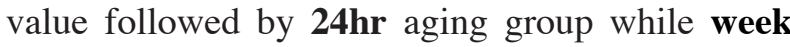
aging group recorded the lowest mean value. The difference in creep mean values between composite groups was statistically significant $(\mathrm{P}<0.05)$.

Table (2) Comparison of creep results (Mean values \pm SDs) as function of composite groups and artificial aging

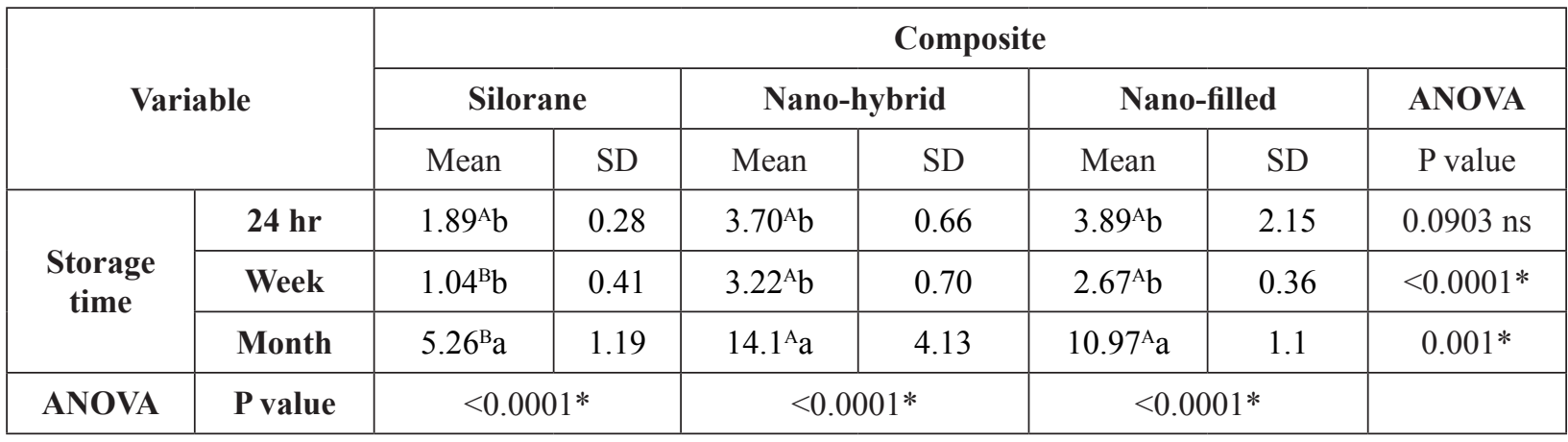

Different superscript letter in the same row indicating statistically significant between composite (Tukey's test; $p<0.05)$. Different subscript letter in the same column indicating statistically significant between aging (Tukey's test; $p>0.05) *$; significant $(p<0.05)$ $n s$; non-significant ( $p>0.05)$

\section{DISCUSSION}

Recent advances in resin restorative materials as well as an increased demand for aesthetics have simulated a greater increase in the use of resin composite in anterior and posterior teeth ${ }^{(23)}$. Despite the remarkable developments in the technology of the composite resin restorative materials, clinical failures of composite restorations are still reported, particularly when composites are placed in stress bearing areas ${ }^{(24)}$.

Among the marketed resin composite materials, three composite materials having different matrix structure and filler size but similar in percentage of filler content were selected. According to type of organic matrix; silorane is siloxane and oxirane matrix structure, nanofilled composite is methacrylate modified polysiloxane and nanohybrid composite is methacrylate-based composite.

The chemical composition of the monomer affects the light attenuation and the mechanical properties of the material There were many factors which were very important in standardization of the testing procedure including: light intensity (distance of the light guide tip from the resin composite, power density and exposure duration), thickness of the specimen, material composition, shade and opacity of the composite resin ${ }^{(25)}$. 
All the test specimens were of the same shade (A2 vita shade). The experimental variables were all standardized in this study. All specimens were treated identically throughout this study.

\section{Shear punch strength:}

A shear punch test originally advocated by Roydhouse in 1970 has been evaluated as a means of comparing the mechanical properties of a wide range of dental restorative materials. The shear punch test was advocated on the grounds of its simplicity and particularly the ease with which good quality specimens can be done ${ }^{(26)}$.

In the current work, all specimens fractured by a clean punching-out of a central disc of material having a diameter equivalent to that of the punch. This ensures that fracture had occurred purely by a shear mechanism. We have previously shown ${ }^{(26)}$ that an important feature of the test is the use of a standardized and controlled restraining torque in order to prevent bending of the specimen during testing. This was done in the current work. Although, the preparation of specimens is simple, reliable and involves efficient use of material, the test outcome is dependent upon the accurate machining of the test rig.

The results of the work clearly demonstrated the effects of filler content and filler particle size on mechanical properties. When filler volume fraction of composite was increased shear, strength increased. This is in agreement with previous work and suggests that resin particle interfaces can act as sites for crack initiation and propagation in regions where tensile stresses arise. Hence, it is clear that the reinforcing effect of glass fillers only remains effective as long as the particulate filler phase and resin matrix phase are bonded together ${ }^{27,28)}$.

One study ${ }^{(29)}$ has reported that flexural strength is not expected to increase continuously once the filler content is raised above a certain critical level, due to the greater possibility of voids being incorporated. This confirms a finding of Bowen et al. ${ }^{(28)}$ that smaller filler particles have a more pronounced effect on strength than larger particles at the same volume fraction. Although increasing filler content will reduce shrinkage, there may be a detrimental effect on other properties.

The chemical environment is one aspect of the oral environment that could have an appreciable influence on the in vivo degradation of composite resins. The most common reasons for failure of composite restorations are bulk fracture and secondary caries. The fact that a composite material can perform well in one patient but may degrade, wear and fracture prematurely in another, is attributed to individual variations including the type of occlusion, diet and salivary and plaque compositions ${ }^{(30)}$.

\section{Viscoelastic behavior:}

The creep deformation is a significant aspect of the mechanical performance of polymer-based materials. It has been reported that if a resin-based material has high creep strain, this will adversely affect its resistance to mechanical stress and thus influence the long-term clinical durability of the restorations ${ }^{(31)}$. Therefore, this study was conducted to evaluate the creep deformation of some newly introduced resin-composites.

An inherent mechanical problem of polymeric filled materials such as composite resins is their viscoelasticity, which reduces their capacity to resist deformational change under load, especially under conditions of moisture from saliva and fluctuating temperatures. Thus, creep is defined as the time-dependent plastic deformation, or strain, of a material under a static load well below its conventional elastic limit.

The results of the present study showed that highest creep values were recorded to Nanohybrid composite, then lower creep values to nano ceramic composite to the lowest values to the silorane composite. The variation of the results under the same conditions of loading and temperature suggests that compositional differences among the materials may have a considerable influence in viscoelastic behavior ${ }^{(32)}$. So, we agree with Watts, 
and H. Y. Marghalani whom mentioned that silorane composite exhibited viscoelastic stability ${ }^{\left({ }^{(33)}\right.}$.

The higher creep resistance of nanohybrid ceramic composite can be attributed predominantly to their high filler content of a well-balanced combination of different sizes and types, which, in turn, minimize the amount of polymeric resin component. Similar findings have been reported in previous studies in which heterogeneously filled composites showed a marked decrease in their creep properties compared to homogeneously filled ones ${ }^{(34)}$.

Moreover, we agree with Renata. V Mesquita et al. who mentioned that water sorption may alter the viscoelastic properties due to plasticizing degradation effect - two distinctly different mechanisms Absorbed water causing sorption expansion, increasing the effective free volume and the ease of movement of chain segments, thus reducing the elastic modulus and increasing the viscous modulus and loss tangent ${ }^{(35)}$.

Filler content plays an important role in the creep resistance of composite resins as silorane-based composite possesses the lowest filler content when compared to both methacrylate-based materials, the reason for its same creep resistance should be attributed to other factors possibly to its monomer composition or filler coupling ${ }^{(36)}$. Siloranes were developed as monomers with four polymerisable cycloaliphatic oxirane moieties giving a higher crosslink density and thus a better creep resistance ${ }^{(37)}$.

The results of the present study are in disagreement with the study of El-Safty et al. ${ }^{(31)}$ who found that Creep deformation of all studied resin-composites increased with wet storage. This difference may be due to the difference in the methodology because they compare between dry and wet aging for $24 \mathrm{~h}$.

The absorption of moisture by the resincomposites leads to the degradation of both strength and stiffness of composites ${ }^{(38)}$. The effect of water on creep behavior in terms of plasticization is evident in the literature. The presence of water and other fluids has the potential to induce swelling and peeling stress in the structure, in addition to a plasticizing effect on the polymer matrix as well as deboning of the filler from the matrix, all of which can lead to increased creep formation ${ }^{(31)}$.

\section{CONCLUSION}

1. The analyzed nano filled composite revealed higher shear strength, when compared to silorane composite material and nano hybrid composite.

2. The analyzed nano hybrid filled composite showed higher creep value, when compared to silorane and nanofilled composite materials.

\section{REFERENCES}

1. Van Meerbeek B, De Munck J, Yoshida Y, Inoue S, Vargas M, Vijay P, et al. Adhesion to enamel and dentin: current status and future challenges. Operative Dentistry-University of Washington. 2003; 28(3):215-35.

2. Deliperi S, Bardwell DN. An alternative method to reduce polymerization shrinkage in direct posterior composite restorations. The J Am Dent Asso. 2002;133(10):1387-98.

3. Hse KM, Wei SH. Clinical evaluation of compomer in primary teeth: 1-year results. The J Am Dent Asso. $1997 ; 128(8): 1088-96$

4. Combe E, Burke F. Contemporary resin-based composite materials for direct placement restorations: packables, flowables and others. Dental update. 2000;27(7):326-32, 34-36.

5. Hahnel S, Henrich A, Rosentritt M, Handel G, Bürgers R. Influence of artificial ageing on surface properties and Streptococcus mutans adhesion to dental composite materials. J Mater Sci: Materials in Medicine. 2010;21(2):823-33

6. Powers J, Sakaguchi R. Craig's Restorative Dental Materials. $13^{\text {th }}$ ed. St. Louis: Mosby Co; 2012.162-70.

7. Deb S, Sehmi H. A comparative study of the properties of dental resin composites polymerized with plasma and halogen light. Dent Mater. 2003; 19(6):517-22

8. Anusavice K. Phillip's Science of Dental Materials. $11^{\text {th }}$ ed. St. Louis, Missouri: W.B. Saunders Co; 2003. 400-10.

9. Mitra S, Wu D, Holmes B. An application of nanotechnology in advanced Dent Mate. J Am Dent Asso 2003;134(10):1382-90

10. Bayne S, Heymann H, Swift E. Update on dental composite restorations. J Am Dent Asso 1994;125(6):687-701. 
11. Attar N. The effect of finishing and polishing procedures on the surface roughness of composite resin materials. J Contemp Dent Pract. 2007; 8(1):27-35.

12. Suzuki T, Kyoizumi H, Finger WJ, Kanehira M, Endo T, Utterodt A, et al. Resistance of nanofill and nanohybrid resin composites to toothbrush abrasion with calcium carbonate slurry. J Dent mater . 2009; 28(6):708-16.

13. Sangermano M, Ortiz RA, Urbina BAP, Duarte LB, Valdez AEG, Santos RG. Synthesis of an epoxy functionalized spiroorthocarbonate used as low shrinkage additive in cationic UV curing of an epoxy resin. Eur Poly Jour. 2008; 44(4):1046-52

14. Kim J-G, Chung C-M. Trifunctional methacrylate monomers and their photocured composites with reduced curing shrinkage, water sorption, and water solubility. Biomater. 2003;24(21):3845-51.

15. Braga RR, Ferracane JL. Alternatives in polymerization contraction stress management. Critical Reviews in Oral Bio \& Med. 2004;15(3):176-84

16. Navarra CO, Cadenaro M, Armstrong SR, Jessop J, Antoniolli F, Sergo V, et al. Degree of conversion of Filtek Silorane Adhesive System and Clearfil SE Bond within the hybrid and adhesive layer: an in situ Raman analysis. Dent Mater. 2009;25(9):1178-85.

17. Ferracane JL. Developing a more complete understanding of stresses produced in dental composites during polymerization. Dent Mater. 2005;21(1):36-42.

18. Furuse AY, Gordon K, Rodrigues FP, Silikas N, Watts DC. Colour-stability and gloss-retention of silorane and dimethacrylate composites with accelerated aging. J Dent. 2008;36(11):945-52.

19. Yesilyurt C, Yoldas O, Altintas SH, Kusgoz A. Effects of food-simulating liquids on the mechanical properties of a silorane-based dental composite. Dent Mater J. 2009;28(3):362-67.

20. Leinfelder KF. New developments in resin restorative systems. The J Am Dent Asso. 1997;128(5):573-81.

21. Attar N. The effect of finishing and polishing procedures on the surface roughness of composite resin materials. $\mathrm{J}$ Contemp Dent Pract. 2007;8(1):27-35.

22. Palin W, Fleming G, Burke F, Marquis P, Randall R. The influence of short and medium-term water immersion on the hydrolytic stability of novel low-shrink dental composites. Dent Mater. 2005; 21(9):852-63.

23. Cadenaro M, Biasotto M, Scuor N, Breschi L, Davidson CL, Di Lenarda R. Assessment of polymerization contrac- tion stress of three composite resins. Dent Mater. 2008; 24(5):681-85.

24. Garoushi S, Vallittu PK, Watts DC, Lassila LV. Effect of nanofiller fractions and temperature on polymerization shrinkage on glass fiber reinforced filling material. Dent Mater. 2008; 24(5):606-11.

25. Lutz F, Phillips RW. A classification and evaluation of composite resin systems. J Prosth Dent. 1983; 50(4):480-88.

26. kejima I, Nomoto R, McCabe JF. Shear punches strength and flexural strength of model composites with varying filler volume fraction, particle size and silanation. Dent Mater. 2003; 19(3):206-11.

27. Bowen R. Properties of a silica-reinforced polymer for dental restorations. J Am Dent Asso (1939). 1963; 66:57-66.

28. Bowen R. Effect of particle shape and size distribution in a reinforced polymer. J Amer Dent Asso (1939). 1964; 69:481-95.

29. Hara R, Nemoto K. Studies on dental restorative composite resin-influence of shape and ratio of filler on the physical properties. Jap J Dent Mater. 1986; 5:1-16.

30. Fares H. The effect of Dietary materials on shear punch strength and surface texture of a nanofill and a microhybrid composite A one-year study. Life Sci J. 2013; 10(4):115-21.

31. El-Safty S, Silikas N, Watts D. Creep deformation of restorative resin-composites intended for bulk-fill placement. Dent Mater. 2012; 28(8):928-35.

32. Nakayama WT, Hall DR, Grenoble DE, Katz JL. Elastic properties of dental resin restorative materials. J Dent Res. 1974; 53(5):1121-26.

33. Watts D. Elastic moduli and visco-elastic relaxation. J Dent. 1994; 22(3):154-58.

34. Sanchez C, Laine RM, Schubert U, Chujo Y. Symposium EE. Ann Arbor. 2004;1001:48109-36.

35. Mesquita RV, Axmann D, Geis-Gerstorfer J. Dynamic visco-elastic properties of dental composite resins. Dent Mater. 2006; 22(3):258-67.

36. Awad D, Ilie N. Effect of polymerisation and ageing on the incremental bond strength of ormocer-based dental materials. Clin oral invest. 2013; 17(5):1339-47.

37. Lien W, Vandewalle KS. Physical properties of a new silorane-based restorative system. Dent Mater. 2010; 26(4):337-44

38. Bledzki A, Gassan J. Composites reinforced with cellulose based fibers. Progress in poly sci. 1999; 24(2):221-74. 